\title{
FUNDACIÓN DE LA UNIVERSIDAD PÚBLICA DEL HUILA: AÑOS DEL ITUSCO
}

\author{
María Clara Ibarra Losada \\ Magister en Historia Universidad Nacional de Colombia \\ Docente Universidad Surcolombiana \\ mariaclarai@yahoo.com
}

\section{Introducción}

Por primera vez se realiza el estudio de la Universidad del Huila, desde un contexto histórico de conjunto donde al sintetizar fuentes de información que se encontraban dispersas, se determina por qué se fundó en ese momento y qué la condiciona a lo que es hoy día. Se presenta como un aporte a la historia de la región por cuanto sale de la mentalidad parroquial, para ubicar su contenido en la historia del país y del mundo. La idea de universidad institucionalizada en el Medioevo, inmersa en lo político, evolucionó hasta nosotros y su desarrollo actual no podría entenderse sin el conocimiento de sus orígenes.

La dinámica del continente europeo marca nuestro rumbo educativo, económico, político, cultural y científico. Rasgos de este proceso se podrán encontrar en las etapas señaladas, tanto a través de la consulta de fuentes primarias, como secundarias que permitieron el acceso a documentos y el abordaje de entrevistas, en una aproximación a los hechos históricos que marcaron el surgimiento de la Universidad Surcolombiana.

Este ejercicio investigativo intenta dar respuesta a algunos interrogantes que surgieron en una de las etapas de la investigación como son: ¿Dónde surge la universidad como institución de educación superior y en qué contexto político, socio-económico, cultural, científico y educativo? ¿Qué factores sociales, políticos y culturales determinaron el surgimiento de la universidad en Colombia? ¿En qué circunstancias del contexto nacional se aprueba el proyecto educativo de creación de la Universidad Surcolombiana? ¿Qué necesidades reales y sentidas motivaron la idea de la creación de la Universidad Surcolombiana? ¿Cuál era la dinámica del departamento del Huila en el período en que empieza a gestarse la creación de la universidad para la región? ¿Qué representó el Instituto Universitario Surcolombiano, ITUSCO, como plataforma de lanzamiento de la creación de la universidad? ¿Cuál fue el proyecto inicial que propuso la creación de la Universidad y por qué tardó once años en hacerse realidad? ¿De qué manera las poblaciones orientaron propuestas educativas o legislativas a favor de la creación de la universidad? ¿Qué estaba ocurriendo en el contexto nacional en el momento en que se presenta el proyecto educativo que da paso a la Ley $55 \mathrm{y}$, finalmente, a ITUSCO?El trabajo de investigación histórica se articula en tres acápites.

\section{La universidad como representación del espíritu medieval}

Presenta la evolución general de la universidad desde la Europa medieval hasta los inicios de la Modernidad. Muestra la universidad como reflejo de un movimiento corporativo que aglomeró un grupo de hombres con unos mismos propósitos y buscando el mismo objetivo; en su momento dichas comunidades buscaban proteger a los profesores contra el canciller, el obispo, el rey o quien fuera que intentase ejercer sobre ellos un dominio excesivo.

La esencia que la determinó como tal, las características fundamentales de una época que marcó su nacimiento, las primeras universidades del Medioevo que durante tres siglos tuvieron como promotores las órdenes religiosas. Muestra el surgimiento de la institución de educación superior en el marco de la dinámica de una sociedad que la 
definió y caracterizó y que se vio influenciada de manera marcada por la Iglesia.

La historia de la universidad como institución se remite a la época medieval, aproximadamente hacia el año $1100, y$ en este sentido considerada la segunda institución más antigua del mundo Occidental, después de la Iglesia. Su nacimiento se dio en una época que la representó, que la definió y la caracterizó en atención a los cambios que se estaban gestando a nivel social, económico, político, cultural, científico y educativo.

De estas causas específicas merece mencionar cinco aspectos que por su complejidad se constituyeron en piezas clave del nacimiento y desarrollo de las universidades: la influencia de la cultura árabe, que alcanza gran altura en los siglos X, XI, y XII, y que contaba con centros de enseñanza superior con carácter científico; los escritores clásicos griegos y el mismo maestro Aristóteles llegan a Europa a través de la cultura árabe. La nueva economía monetaria de mercado, que dinamizó las relaciones comerciales y, por lo mismo, determinó el surgimiento de distintas estructuras sociales de convivencia en las ciudades, y el nacimiento de una nueva clase social: la de los artesanos libres y jornaleros.

El sentido gremial de la sociedad del Medioevo, que posibilitó que el hombre medieval se organizara en corporaciones animadas por aspiraciones y propósitos comunes. La presencia del pensamiento islámico, judío, árabe y latino con los grandes maestros y filósofos, abriría las puertas de un renacimiento cultural. El surgimiento de nuevas estructuras económicas, que incidió notablemente en el aumento de los alumnos en las escuelas, las cuales giraban en torno a una principal y requería de un nuevo centro que las reuniese a todas en una misma jurisdicción jerárquica: la universidad.

Presentar la historia de la universidad es acercarse al origen mismo de la Escuela o la Educación Institucionalizada, donde aparece como término más antiguo y que se asimilaba directamente con el sentido de lo que fue la universidad desde sus orígenes, el Studium Generale, directamente relacionado con las escuelas catedralicias, que tenían un carácter eminentemente eclesiástico y que dieron paso al surgimiento de la universidad.
Luego de conformarse las universidades más antiguas como fue la de Bolonia, París, Oxford y Salamanca, sus modelos se expandieron por Europa y por Latinoamérica, poco después de la conquista emprendida por los españoles y portugueses, como fruto de la tarea civilizadora que la Iglesia se había impuesto.

En definitiva, se puede concluir que las antiguas universidades europeas se agruparon por zonas geográficas, que marcaron una realidad histórica y la misma expansión del continente. En los dos últimos siglos de la Edad Media (s. XIV-XV) se observó un aumento significativo de universidades, que recorrieron desde el Mar Mediterráneo, occidente de Europa, Península Escandinava hasta el oriente, Polonia y parte de Hungría. En este mismo período unas ochenta ciudades fueron sede de un StudiumGenerale. Toda América Latina recibió la estructura de la universidad medieval a través de España y Portugal, y su contenido y su forma a través del código de Napoleón.

La enseñanza estaba fundamentada por una base ideológica común y un carácter internacional. Las reformas alteraron su organización interna y externa y dieron paso a la formación de tres tipos o modelos de universidades europeas: el inglés, el francés y el alemán, los cuales representaban los rasgos de las universidades medievales. Las instituciones adquirieron un carácter nacional, tanto en sus condiciones académicas como en sus requisitos generales, es decir, en su organización interna y externa. En el siglo XV la universidad es concebida como un instrumento político que ayuda a la Corona en su papel dinamizador y modernizador de la sociedad.

En el siglo XVII nace la ciencia empírica, con las teorías de René Descartes y Bacón, las cuales se extienden por toda Europa, dando una nueva connotación a la investigación científica. La universidad adquiere una categoría más amplia por la pluralidad de saberes y de culturas, y el avance de la ciencia y la tecnología que hacen de esta un organismo en continua renovación. La estructura y dinamismo de la universidad europea tuvo continuidad con el papel expansivo en América y en otras zonas. Después del descubrimiento de América, España, Portugal e Inglaterra impulsaron 
instituciones universitarias en las nuevas tierras conquistadas.

En 1538 abre sus puertas la primera Universidad de América: La Universidad Santo Tomás de Aquino en Santo Domingo, fundada por los dominicos. Los Jesuitas, por su parte, crearían las de México y San Marcos (Lima) en 1551, el Colegio de Córdoba (Argentina) en 1611, La Universidad Javeriana (Bogotá) en 1622, las de Santiago de Chile y Chugisaca (Bolivia) en 1624. Y así sucesivamente se irían abriendo nuevas universidades en Argentina, Chile, Perú, Venezuela, Cuba y Ecuador.

\section{La educación superior en Colombia}

Se refiere a la educación superior en Colombia y presenta a grandes rasgos la evolución de la educación en el país. Empieza con la Colonia, donde se establecieron las primeras escuelas de enseñanza de las primeras letras y los primeros colegios, en la dinámica que posteriormente dio paso a la fundación de las primeras universidades. En ello se identifican los primeros centros de enseñanza superior y algunas características de su dinámica educativa, tanto en lo relacionado con la enseñanza como con el factor político, económico y social.

En Colombia la educación recibió la influencia de los modelos europeos y, como en el antiguo continente, se expandió por todo el territorio una vez instalada la Real Audiencia en 1550. Se autorizó a conventos para impartir instrucción a clérigos y seglares en gramática y lectura, con lecciones que fueron impartidas por franciscanos, agustinos y dominicos, esencialmente.

Para la época se destacó la fundación del colegio de San Bartolomé en 1605 considerado el más antiguo de Colombia; aparece en 1654 el Colegio Mayor de Nuestra Señora del Rosario, creado por Fray Cristóbal Torres. Además, la Universidad Javeriana, creada con autorización Real en 1623, en donde se otorgaron los primeros títulos de doctor en Jurisprudencia y Teología. A partir de 1636 empieza el funcionamiento de la Universidad Tomística; asimismo, se abrieron seminarios en Popayán, Tunja y Cartagena.

El Estado colonial sólo conoció en términos de política educativa el concepto de escuela pública elemental en la segunda mitad del siglo XVIII, bajo los reyes Borbones. En el reinado de Carlos III se dio un impulso a la educación. Sin embargo, por las evidencias, tal impulso no representó una ayuda significativa por cuanto las escuelas públicas de las "primeras letras" que estaban bajo el control de los cabildos de villas y ciudades, tenían un sostenimiento a partir de las rentas denominadas de "propios", las cuales representaban tan poco que ni siquiera servían para el pago del sueldo de los maestros.

Así, pueblos, villas y ciudades no tenían suficientes recursos para fundar y sostener las escuelas; por lo mismo, al terminar la dominación española sólo se contaba con un débil sistema de escuelas públicas. Esta situación se agravaba ante la bajísima preparación de los maestros, pues algunos apenas sabían leer y escribir; sólo estaban preparados para enseñar el rezo y la doctrina cristiana. Ante esta escasez, el maestro privado tuvo cierta preponderancia.

En este período las relaciones entre el Estado y la Iglesia se encontraban reguladas por el Real Patronato de Indias, donde la Iglesia se situaba bajo el control de la Corona de España. La contrapartida era cristianizar las tierras conquistadas y favorecer la prosperidad espiritual y material de la Iglesia, a quien se le otorgaba responsabilidad especial sobre la educación, los hospitales y las instituciones caritativas, como uno de los principales agentes de poder civil.

Los primeros atisbos de universidad en la época colonial se dieron desde la primera etapa de la colonización española. Una vez instalada la Real Audiencia en 1550, se autorizó a conventos para impartir instrucción a clérigos y seglares en gramática y lectura, donde las lecciones fueron impartidas por franciscanos, agustinos y dominicos. Además de la fundación del colegio de San Bartolomé en 1605, aparece en 1654 el Colegio Mayor de Nuestra Señora del Rosario, creado por Fray Cristóbal Torres. Además, con autorización Real, fue creada la Universidad Javeriana en 1623; allí se otorgaron los primeros títulos de Doctor en Jurisprudencia y Teología. A partir de 1636 empieza el funcionamiento de la Universidad Tomística; 
asimismo, se abrieron seminarios en Popayán, Tunja y Cartagena.

A comienzos del siglo XVIII se encontraba una cantidad significativa de colegios y universidades con autorización para otorgar títulos de licenciados y doctores. Solían tener tres ciclos de estudio: artes, teología y cánones. El ciclo de artes, que correspondía al tradicional Studium Generale de las universidades medievales, era equivalente al bachillerato moderno. Duraba de dos a tres años y en él se enseñaba gramática, retórica, lógica, metafísica, rudimentos de matemáticas y física. El contenido de todas estas materias se tomaban de Aristóteles, Santo Tomás y de los maestros escolásticos. Los de teología y cánones duraban cuatro años. Los exámenes se realizaban cada cuatro meses, en lo que se denominó La tremenda, donde de un texto seleccionado al azar se hacían preguntas, en torno a las cuales se debatía y el jurado emitía su concepto de aprobación o desaprobación. Todo públicamente y en Latín.

En esta época se desarrollo una universidad, para una sociedad con funciones determinadas en 10 sacerdotal y jurídico. Una sociedad agraria, comercial y minera, donde la tecnología y los procedimientos eran muy incipientes y rudimentarios. La misma cultura del momento, incluso de las clases altas, tenía la educación que se requería según las necesidades sociales.

A comienzos del siglo XIX el Virrey Mendinueta se asombraba del atraso en los estudios en los colegios del Rosario y San Bartolomé y en la Universidad Tomística de los dominicos, por lo mismo insistió en la necesidad de crear una universidad pública, la cual se había prometido desde 1774.

Con la proclamación de la República, los nuevos dirigentes se propusieron el establecimiento de un sistema de educación pública. Su formación ilustrada les hizo mirar la educación como la panacea a todas los problemas del dominio colonial español y pensaron, en consecuencia, que con ella sobrevendría la prosperidad, la paz y el orden. Así, la instrucción pública surgió fundamentalmente como una estrategia orientada a la conformación de la nacionalidad, donde un estado interventor sería el encargado de reglamentar la estructura del sistema escolar, y hasta "el régimen moral y de verdad" que regiría el país.

Durante el gobierno de Santander se destaca en este periodo la expedición de decretos que favorecieron la creación de escuelas públicas y propuestas para la consolidación de la instrucción pública. Las relaciones con la Iglesia se transformaron: el clero fue sometido y sus miembros fueron declarados funcionarios públicos, debido a que el Estado se erigió ahora como ente regulador y vigilante del magisterio de la Iglesia, declarandose así el único portador del discurso público.

Bajo esta óptica de la supremacía del Estado sobre lo público, el Congreso de Cúcuta suspendió los conventos menores y utilizó sus bienes para el sostenimiento de los colegios, buscando de esta manera desplazar la intelectualidad muy ligada a los eclesiásticos y liberar a la juventud de la instrucción monástica. En cambio, permitió el establecimiento de escuelas de niñas en los conventos de religiosas, con poder discrecional del ejecutivo para intervenir en su reglamentación. También se destinaron fondos para la creación de casas de educación y la creación de escuelas normales que formarían maestros bajo el método lancasteriano.

Durante la denominada "Guerra de los supremos" en 1840, que determinó la designación de Pedro Alcántara Herrán como Presidente de la República, y con él un período de hegemonía conservadora hasta aproximadamente 1849 , se mantuvo en esta época el control moral en la escuela y se afianzó el sector privado en la educación. El ministro Mariano Ospina Rodríguez orientó reformas y comenzó con la expedición de la Ley Orgánica de Universidades en 1842. Creó la inspectoría para vigilar la asistencia de profesores y alumnos.

Las únicas universidades que funcionaron durante el gobierno de Alcántara fueron la de Primer Distrito, en Bogotá, que incluía las provincias de Antioquia, Bogotá, Casanare, Mariquita, Neiva, Pamplona, Socorro, Tunja y Vélez; la de Segundo Distrito, ubicada en Cartagena, capital de las provincias de Cartagena, Mompox, Panamá, Riohacha, Santa Marta y Veraguas; y la de Tercer Distrito, en Popayán, la conformaban las Provincias de Buenaventura, Cauca, Chocó, Pasto y Popayán con capital en esta 
última ciudad. En 1845 a la universidad del primer distrito asistían 333 esudiantes, en la del segundo 205 y 147 en el tercer distrito.

El incremento de matrícula en la educación primaria se presentó sólo en el sector privado. El gobierno de la época, por su obsesión en dirigir sus políticas hacia la calidad educativa de la escuela pública, descuidó su expansión como tal. Los gobiernos conservadores mosqueristas de 1844-1849, se mostraron más preocupados por la calidad de la escuela pública, que por su expansión, por lo mismo todos los esfuerzos estuvieron dirigidos a la creación y puesta en marcha de la Escuela Normal de Varones, como política oficial que determinaba el establecimiento de normales en todas las provincias, como medio para mejorar la calidad educativa, situación que repercutió en la disminución de las escuelas primarias sobre todo entre los años 18451849.

Con la llegada a la presidencia de Tomas Cipriano de Mosquera, se continuó con los propósitos del gobierno anterior en materia de enseñanzas científicas, además de propiciar una reforma a las universidades dirigida a la flexibilización de estudios y se minimizó el control a la moral, tan importante para los conservadores.

La modernidad en educación comprende las políticas educativas que se impartieron a partir de la segunda mitad del siglo XIX. El territorio colombiano, como colonia de España, fue marginal al surgimiento y desarrollo del pensamiento y de las transferencias territoriales y culturales de la modernidad europea. La realización de la Expedición Botánica y de los procesos asociados con la Independencia, incidieron en la ciencia y en las políticas regionales.

La presidencia del general José Hilario López, basada sobre los principios de libertad, igualdad y tolerancia, dio continuidad a la propuesta liderada después por Mosquera de la libertad educativa y profundizó aún más la descentralización de las responsabilidades educativas. Se suprimieron los reglamentos centralizadores, dejando la organización y el financiamiento educativo bajo la responsabilidad total de las provincias y las localidades. El 15 de mayo de 1850 , por ley del Congreso, se suspendieron las tres Universidades Distritales existentes.
La ley determinó que sería "libre en la República la enseñanza de todos los ramos de la ciencia, de las letras y de las artes". Se especificaba que ya no se requería título universitario para el ejercicio de profesiones científicas, pero que podrían obtenerlo las personas que quisieran en colegios nacionales, provinciales, particulares o seminarios. Se suprimió el grado de bachiller, para dar paso solamente al de doctor en jurisprudencia, medicina y ciencias eclesiásticas. Con la presentación de un examen oral en las materias que indicaba la misma ley. Para tal efecto se crearon escuelas de "artes y oficios", como escuelas de entrenamiento industrial.

Un informe de prensa de 1853 expresaba que en el país "las escuelas y los colegios existían en un estado de pura anarquía", situación que se profundizó al presentarse la división del país en ocho estados soberanos en 1857. Mientras la educación pública entró en un período de crisis profunda, la educación privada se fortaleció en detrimento de la educación primaria pública que se hundió, y con ésta las escuelas Normales que formaban a sus docentes.

Después de un largo periodo de inestabilidad política como consecuencias de las guerras civiles y en golpe de Estado, surge de nuevo la idea de la universidad. El proyecto de ley presentado por José María Samper en 1864 , dio paso a la nueva ley orgánica que probó el Congreso Nacional, "con el objeto de organizar una Universidad Pública en la capital de la República, la que llevará el nombre de Universidad Nacional de los Estados Unidos de Colombia. El decreto fue dictado por el presidente Santos Acosta y el primer rector fue Ezequiel Rojas.

El gobierno radical para superar los desórdenes políticos tan frecuentes en el siglo XIX, visualizaron un reino de paz, basado en la consecución de una ciudadanía ilustrada y en el mejoramiento de la economía del país, según sus consideraciones estos propósitos podrían ser alcanzados con la educación. Se emprende una reforma educativa, que se plasmó en el Decreto Orgánico de Instrucción pública Primaria, que como se ha venido señalando, desde los primeros años de aplicación permitió un progreso significativo en el sector educativo. En importante destacar que el decreto implemento la educación gratuita y obligatoria en instituciones oficiales, así como la libertad de enseñanza religiosa 
en las escuelas.

La Constitución de 1886 y el Concordato de 1887 son los acontecimientos que crearon condiciones para el retorno de la intermediación del maestro por el magisterio de la Iglesia, esta última definida como formadora de maestros de maestros. Durante la dictadura de Rafael Reyes (1904-1909) se profundiza la centralización y modernización del Estado, por lo mismo se contrataron a expertos e ingenieros norteamericanos y europeos para orientar las reformas, que tocaron ante todo las finanzas, gracias a la estabilización de la moneda y el arreglo de la deuda externa.

Para favorecer la industria, el gobierno tomó medidas proteccionistas y concedió subsidios a ciertos sectores de la producción. Se aumentaron las redes de comunicaciones, en especial los ferrocarriles. Asimismo, se presentó la división territorial y se dividió el país en catorce departamentos.

A comienzos del siglo XX los datos presentan todavía un país poco alfabetizado en relación con América Latina. La mayoría de los departamentos tenían una tasa de alfabetización que variaba entre el $25 \%$ y el $35 \%$. Los departamentos del Valle, Caldas, Atlántico y Antioquia, lo mismo que las islas de San Andrés y Providencia y el territorio del Meta, tenían un nivel más alto de alfabetización que el resto de la nación. La educación superior en la época de reforma a la modernidad, comprende la educación que se impartió en el período que empieza en 1920 y culmina en 1960, para dar paso a la denominada "tecnología educativa", que surge después de los años sesenta.

Los acontecimientos de orden económico, discursivo, institucional, social y político, llevaron a grandes transformaciones en la educación, en la forma de gobernar y en la cultura. Los efectos de la sociedad comercial e industrial que emergía fueron determinantes en esa nueva forma de concebir la educación. Durante el gobierno de Alfonso López Pumarejo (1934), se observó como propósito del liberalismo realizar una reforma educativa desde la escuela primaria hasta la universidad.

El gobierno anunciaba la organización del sistema educativo nacionalista, modernizador y democrático que preparara el hombre que necesitaba la industria, los campesinos que requería la agricultura tecnificada y los ciudadanos de una sociedad democrática dinámica e igualitaria, donde se contara con una preparación científica y una conciencia nacionalista.

Corrientes pedagógicas como la Pedagogía Activa 0 Escuela Nueva llegaron al territorio colombiano rescatando propuestas rousseaunianas y de otros pedagogos como Decroly, Chaparede, Dewey, Montessori, entre otros, lo que permitió introducir nuevas metodologías y didácticas sustentadas en la observación, la experimentación y el papel activo de los estudiantes.

Algunos dirigentes liberales, entre ellos Agustín Nieto Caballero, fundaron en Bogotá el Gimnasio Moderno en el año de 1914, que estableció en sus aulas los principios de la "pedagogía activa". El problema educativo del país para Nieto Caballero estaba centrado básicamente en el maestro. Se requería una formación pedagógica y técnica. No luchaba por una revolución educativa sino por una modificación en el aspecto pedagógico y por lo mismo apoyó la comisión extranjera que trabajaría en torno a la metodología de la enseñanza.

A consecuencia del surgimiento de la era industrial en Colombia, surgió una nueva etapa que comienza en el año de 1932 y culminó en el año de 1976. Esta se caracterizó por cambios estructurales que se dieron en la educación superior colombiana y en los procesos de formación de docentes para la educación superior. Se concedió al docente un papel relevante y se le asignaron funciones específicas, especialmente con el surgimiento de la Escuela Normal Superior colombiana que funcionó entre 1936 y 1951, la cual estuvo influenciada por los preceptos de la "pedagogía activa."

Los gobiernos liberales de 1934 a 1946 tuvieron una clara percepción de la importancia del sector educativo en los proyectos de desarrollo económico y social y en el propósito de hacer de Colombia un país moderno y una nación mejor integrada socialmente, basada en una cultura de raíces nacionales más auténticas. Dentro de esas metas trataron de desarrollar una política que abarcara 
todos los estratos de la educación desde la escuela elemental hasta la universidad, dotando al país de un coherente sistema educativo nacional.

En los años de 1948 a 1957 la universidad pública fue intervenida por el gobierno. En este periodo se observa un aumento de universidades privadas, que poco a pocos empezó a superar en alumnos a las universidades públicas por su incapacidad de admitir estudiantes. Se presentan también importantes cambios institucionales y se da la creación de organismos reguladores de la actividad universitaria.

En Colombia se implantó el modelo desarrollista con fines económicos y la educación no se escapó de las políticas de penetración ideológica. Después de los años cincuenta se posiciona el modelo pedagógico de la tecnología educativa, cuyos fundamentos, como ya se ha referido, estuvieron orientados a privilegiar la instrucción sobre la educación, destacando la ciencia y la tecnología como medio y fin.

A pesar de existir muchos argumentos a favor del desarrollo de la enseñanza técnica, en el periodo de 1945-1955, el proceso se registra demasiado lento, lo que al parecer estaba directamente relacionado con el crecimiento industrial que para el periodo se aproximaba al $10 \%$ anual. Por lo mismo lo que se percibía era una preocupación de la racionalización del desarrollo económico más que una urgente necesidad de mano de obra.

Aunque la tecnología educativa comienza a recomendarse a los gobiernos del llamado Tercer Mundo desde finales de la década del 50, en América Latina y particularmente en Colombia, su auge corresponde a los años 60 y 70 . Por estos años se introdujo la televisión educativa con programas conductuales como Plaza Sésamo y se organizan nuevos sistemas escolares e instituciones educativas de instrucción programada y controlada para una capacitación técnica media, como el SENA y los INEM, con currículos diseñados por tecnólogos para ser aplicados por cualquier docente; serían los denominados "currículos a prueba de maestros".

Nuestra crisis, aciertos y desaciertos, y el bajo nivel de desarrollo científico y tecnológico alcanzado y que sobresale más en algunas regiones del país son el reflejo de una nación disgregada, con mínimo nivel de pertenencia, una nación dependiente y que no tiene claridad sobre el camino que debe seguir para orientar su desarrollo verdadero en procura del fortalecimiento institucional y de sus organizaciones así como del mejoramiento real de la calidad de vida de los ciudadanos.

\section{La educación superior en el Departamento del Huila}

Describe el contexto histórico, político, social, cultural y educativo del Huila, desde la primera forma administrativa que tuvo, donde fue denominada Provincia de Neiva, ente administrativo presidido por un gobernador nombrado por el Presidente de la República. Luego su anexión al Estado de Cundinamarca y posteriormente su incorporación al Estado soberano del Tolima, una vez constituida la República de Colombia. Asimismo, se presentan aspectos del desarrollo socioeconómico y su vínculo con el surgimiento de la universidad, la evolución educativa del departamento y de Neiva y el surgimiento del Instituto Técnico Universitario Surcolombiano, ITUSCO.

Una de las etapas de la historia educativa regional hace referencia a la evolución educativa de la provincia de Neiva desde la independencia hasta su transformación en un departamento del Estado de Cundinamarca. En siete períodos se presenta su desarrollo en un contexto económico, social y político, atendiendo las políticas nacionales que se emitían para el sector.

Algunos aspectos a destacar son: Entre 1819 y 1830 , fue evidente el atraso económico de la provincia que contaba con 47.157 habitantes y que por caminos de herradura se acercaba a Popayán y Bogotá. Por su parte, la navegación era muy incipiente por la misma construcción artesanal de las balsas. El sector económico lo dinamizaban, fundamentalmente, la producción cacaotera y la explotación minera; en el periodo 1831 a 1840, la situación de crisis económica persistió, pero algunos de los gobernantes estimularon el crecimiento del sector educativo, por lo mismo prestaron especial interés en aplicar el Plan Educativo de Santander, ratificado por Ley nacional en 1835.

Entre 1847 y 1850, se crean tres colegios, 
constituyéndose en primera instancia la normal por considerar que el ordenamiento educativo debía partir del elemento de una buena educación. De 1845 y 1848 , se presenta aún un estancamiento en la producción y la economía en general. En el plano educativo se impulsó la educación de la mujer y de las clases trabajadoras, pues se instaló una Escuela Normal y se expresó una preocupación general por mejorar la calidad de la educación.

Entre los años 1849 y 1860 , se emprenden una serie de iniciativas para fomentar capitales y fortalecer las provincias: inicia el funcionamiento de la Caja de Ahorros; se crean las escuelas democráticas para impulsar la formación política de las masas, se impulsa la creación de una imprenta, como factor que jugó un papel protagónico en el desarrollo de las naciones más poderosas del mundo; se expide una serie de normas para direccionar la educación; se crea un establecimiento de artes y beneficencia; se produce un considerable desarrollo del comercio, donde figuró la explotación de la quina, los cultivos de cacao, el ganado, sombreros y en menor proporción el oro y el cuero de pelo.

La provincia de Neiva figuró como tal hasta el 15 de septiembre de 1857 , cuando pasa a ser parte del Estado de Cundinamarca hasta el 12 de abril de 1861. Como el nuevo territorio no poseía un código educativo, las autoridades dispusieron que la educación se regiría por las normas vigentes en las provincias que lo conformaban. Esta anexión de la Provincia de Neiva al Estado de Cundinamarca trajo como consecuencias que el colegio Santa Librada y el San Simón fueron cerrados hasta que se aprobara el código educativo. Esta situación igualmente llevó al cierre del Colegio de Niñas, de la Escuela Normal y de la totalidad de las escuelas que aún funcionaban en 1857 y que significó a su vez un estancamiento económico y social.

El 12 de abril de 1861, el General Mosquera reconociera por decreto la existencia del Estado soberano del Tolima, conformado por los territorios de la provincia de Neiva y Mariquita. Como consecuencia, en el nuevo Estado se presentó una crisis económica, pues las escuelas fueron clausuradas y sus recursos pasaron a manos de los grupos enfrentados. Los colegios, por su parte, sirvieron de cuartel. En los 25 años de existencia del
Estado Soberano del Tolima direccionaron su desarrollo liberales independientes o mosqueristas, conservadores y liberales radicales. El Estado Soberano del Tolima, para su administración, se dividió en los Departamentos Norte, Centro y Sur. El Departamento Sur comprendía la antigua provincia de Neiva.

El liberalismo radical emprendió una reforma educativa que se plasmó en la educación primaria de 1870 y contenida en el DOIP (decreto orgánico de instrucción púlica). Se presentó un significativo avance educativo, pero surgieron contradicciones entre algunos miembros del clero y el conservatismo, que llevaron finalmente a que en mayo de 1876 se desatará una guerra en el Cauca, con el objeto de enfrentar al Gobierno central. El conflicto se generalizó en el país y en julio de 1876, el gobierno del Tolima declaró turbado el orden público.

Al terminar el año los liberales ganan la guerra, lo cual afecta nuevamente la educación. En casi todo el país las normales y escuelas primarias fueron cerradas; las aulas de clases fueron cuarteles, lo que determinó la destrucción de libros, muebles y hasta edificios. En los 23 años de existencia del Estado fueron frecuentes los conflictos armados, como los cambios de gobernantes y sedes de los mismos.

Con la nueva Constitución de 1886 se declara el país como una república unitaria y centralista y se pasa de Ios antiguos Estados Soberanos a Departamentos. El Estado Soberano del Tolima pasa a ser Departamento del Tolima o Tolima Grande, al que continuó adscrito el territorio huilense hasta el año de 1905 y se subdividió en provincia del Norte, del Centro y del Sur.

A finales del siglo XIX, la situación económica del Huila era preocupante, pues los precios de los productos agropecuarios presentaban alza sostenida, lo que contribuyó con la generalización de la pobreza. A esto se sumaba el reducido número de empresas y de actividades productivas rentables, los bajos ingresos, y el descenso en los precios internacionales del café.

Las secuelas de la Guerra de los Mil Días (18991902), que se desarrolló en un momento de crisis 
económica, fiscal y política, se sintieron aún a comienzos de siglo, en los primeros decenios del siglo XX. Aunque el Huila no fue un escenario directo de las acciones militares fue afectada tanto por las pérdidas humanas, como por la problemática social que desencadenó el abandono de fincas y propiedades, las contribuciones a los fondos de guerra, empréstitos forzosos, impuestos de guerra, las cuotas de ganado, las cuotas de mercancías. Estos aspectos afectaron de manera directa la economía del territorio.

En 1905 el naciente departamento del Huila contaba con dos provincias: la del Sur con 80.741 habitantes y 14 municipios; la de Neiva, con 63.107 habitantes y 12 municipios. El total de la población sumaba 143.848 habitantes. La economía de la provincia del Sur, que tenía como capital a Garzón, se caracterizaba principalmente por la ganadería, la agricultura y la fabricación de sombreros de Suaza. En la provincia de Neiva, del mismo nombre su capital, se trabajaba con el ganado y el cultivo de cacao.

En los primeros años se muestran en todas las poblaciones huilenses las dificultades propias de los territorios en lento crecimiento: una dinámica económica muy incipiente y, por lo mismo, un lento desarrollo. El sistema de transporte terrestre se daba a través de caminos de herradura. El sistema fluvial funcionó mediante el uso de champanes; la navegación a vapor entre Honda y Neiva no logró establecerse. Estos sistemas se constituyeron en las vías para el ampliar la vinculación con otras regiones y mercados.

Sólo hasta 1938, después de la presión ejercida por el pueblo huilense, llegaría el ferrocarril a Neiva. En esta época avanzaba también la construcción de carreteras que pronto dejarían en el pasado los caminos de herradura y la navegación en champanes y canoas.

El proceso de industrialización que empezó en el país a fines del siglo XIX aumentó en los primeros decenios del siglo XX. Los centros de mayor empuje industrial se ubicaron principalmente en Medellín, Bogotá, Barranquilla, Cartagena y Cali. El Huila, como área débil y periférica, quedó rezagado del proceso de industrialización, entre otras razones porque no tenía amplias posibilidades de mercado. No se contaba con fuerza de trabajo calificada y de asesoría técnica, ausencia de créditos, mal estado de vías y carencia de energía eléctrica.

Su paso de la economía tradicional a la moderna fue lenta y compleja: se trataba de pasar de una ganadería extensiva de bajos rendimientos a una agricultura moderna, donde el arroz empezaba a figurar como un importante renglón de la economía. Es importante concluir que el Huila no logró conectarse realmente al mercado mundial, ni con el proceso de industrialización que había iniciado el país, pero sí logró vincularse con los centros de mercado urbano-industriales mediante la oferta de productos agropecuarios.

La vida pastoril, que había dejado huella en el pueblo huilense, daba paso en los años 60 al progreso con una agricultura diversificada y tecnificada donde, con mejores vías de comunicación y medios de transporte, se vinculaba con los mercados extrarregionales. La economía huilense ha estado adscrita, desde sus primeros tiempos, a la producción de bienes agrícolas $y$, por lo mismo, se encuentra condicionada a los períodos de auge y crisis de este renglón de la economía.

Durante los primeros diez años del siglo XX, la crisis del departamento no permitía el avance en el desarrollo educativo. Para los años siguientes, con la llegada al poder de la Unión Republicana (alianza de un sector conservador y un sector liberal) cambió el panorama de la instrucción pública en el departamento.

En atención a los requerimientos de una región que proyectaba su economía en el ámbito nacional y que requería por lo mismo profesionales que lideraran el desarrollo regional, el gobierno departamental implementó desde 1910 un programa de becas de estudios. Un nuevo pico se presentaría en la educación huilense en lo corrido de la década de 1920. Las reformas y planes económicos emprendidos por la Gobernación del Huila mostraron que la acción sobre la escuela debía responder a nuevas prioridades. La escuela dejó de ser entendida como espacio dedicado a la formación moral y cristiana, y se le imprimí́ la idea de empresa de transformación social, desde donde podía intervenir el gobierno departamental y municipal para el 
mejoramiento de las condiciones de los pequeños comerciantes y aparceros oprimidos por los grandes terratenientes ganaderos.

De esta forma se concibieron (junto a las reformas económicas de redistribución de tierras e impulso a la manufactura, que no verían sus frutos sino hasta ya entrada la década de 1930), la creación de fondos escolares para vestimenta y alimentación, la profesionalización del docente y la concepción del maestro como motor del desarrollo. De esta manera se quiso facilitar la asistencia estudiantil a los planteles.

La década de 1940 inició con fluctuaciones en el desarrollo de la educación debido a los inconvenientes generados por las variadas crisis económicas sufridas en el departamento en las primeras tres décadas del siglo y por los brotes de violencia que ya se veían en los municipios. De igual forma, el crecimiento demográfico acelerado de Neiva repercutió en el nivel educativo. El número de estudiantes inscritos en escuelas creció en beneficio de la enseñanza urbana y en especial de carácter privada, mientras el crecimiento rural fue mínimo en comparación con los resultados obtenidos en décadas anteriores. La década de 1950 quizá fue la más dinámica en cuanto a crecimiento de la escolaridad secundaria, triplicándose el número de alumnos inscritos y duplicándose el número de planteles que prestaban el servicio.

Entre 1943 y 1953 se duplica la educación secundaria del Huila; el número de estudiantes pasa de 743 a 1.717 , repartidos entre 20 colegios, 8 oficiales y 12 privados. De 1953 a 1963 se triplicó, pasando de 1.727 a 4.520 alumnos entre 39 colegios. Finalmente, en el período entre 1963 y 1973 (fundamental para el proceso de investigación histórica, por el salto en la cobertura en educación secundaria sin precedentes en este nivel), pasa de 4.520 a 20.427 estudiantes, un aumento de 4.5 veces.

Surgen en este periodo de la historia del departamento propuestas de creación de la universidad, pero la que finalmente se concretó fue la gestada por algunos líderes políticos y culturales que abrieron caminos por el Huila despertando en sus gentes el anhelo de una universidad como un propósito colectivo. En este punto merece especial atención el trabajo realizado por el parlamentario Guillermo Plazas Alcid, quien como líder político no solo presentó en 1968 el proyecto que dio paso a la Ley 55 que creaba el Instituto Universitario Surcolombiano que abrió sus puertas el 30 de marzo de 1970, bajo la dirección de Marco Fidel Rocha, sino que asumió el proyecto de universidad como una meta personal y por lo mismo promovió una conciencia colectiva desde los medios de comunicación para que el pueblo huilense entendiera la importancia de la creación de un centro de estudios superior y despertara aún más ese clamor popular que venían gestando líderes culturales del departamento.

Armando un rompecabezas de todas las situaciones, hechos, movimientos y personajes que estuvieron vinculados con el surgimiento de la Universidad del Huila y que finalmente promovieron su creación se debe recoger como primera ficha de ese paisaje histórico, el período de masificación de la educación secundaria, a través de colegios públicos, parroquiales, privados, diurnos y nocturnos, donde aumenta la base de bachilleres deseosos de seguir adelante en su formación.

La segunda ficha sería el desarrollo urbano del departamento que requería la mano de obra y el empleo. La tercera podría ser la necesidad de tipo social de la formación de profesionales que jalonaran el desarrollo económico y educativo. La cuarta, la política de formación tecnológica impulsada por el gobierno nacional; el plan ATCOM y los planes institucionales abogaban por el establecimiento de una mano de obra calificada, hecho que no materializó la creación de la universidad, pero sí su nivel tecnológico. La quinta, el movimiento social liderado por el Grupo Cultural Entrada Libre y las acciones de la denominada Operación Huila, que despertaron la conciencia de un pueblo que empezó a marchar por el encuentro con la universidad, en un esfuerzo tanto de colectivos organizados como de esfuerzos individuales.

\section{Conclusiones}

La universidad surge en la cultura occidental en un medio en que el cristianismo se constituía en el centro de la historia. Por lo mismo, la Iglesia desde un comienzo tuvo un papel protagónico en la 
creación, dirección y administración de los centros de enseñanza superior. El proceso de fundación se presentó desde el siglo XII hasta el XV en un momento donde se venían gestando cambios socioeconómicos, políticos, culturales y científicos que favorecieron el nacimiento de la institución de estudios superiores.

Las primeras universidades estuvieron vinculadas con la problemática social de sus regiones de origen, y fueron a su vez determinantes en el desarrollo de los pueblos, por cuanto se constituyeron en centros del saber y por lo mismo fueron consultadas por los gobernantes para tomar decisiones fundamentales en la consolidación de los estados.

Los modelos de las primeras y más prestigiosas universidades europeas no sólo se propagaron en Occidente, sino que estuvieron presentes en Latinoamérica desde el mismo momento del período de conquista por parte de portugueses y españoles. Con éstas nos llegó el componente pedagógico, los planes de estudio, la estructura y hasta la forma de gobierno.

La universidad no ha sido nunca un recinto de sabiduría alejada del devenir histórico de las sociedades. Por el contrario, es claro que surgió como producto de procesos sociales, de transformaciones culturales, cambios de mentalidad, nuevas relaciones comerciales $y$, por lo mismo, debe estudiarse en su inserción histórica, sus conexiones con el poder, la economía, los grupos sociales, los intereses, la ideología, creencias, actitudes y sensibilidades de cada momento. Es decir, debe estudiarse de acuerdo con los diferentes planos que conforman su red de relaciones y condicionamientos.

Hoy las instituciones de educación superior cuentan con mayor autonomía, que en la mayoría de los casos no han sabido manejar, dando paso a contiendas de partidos, intereses particulares, corrupción en todos los estamentos, poca pertenencia institucional de la comunidad universitaria, pérdida de la función social de la institución, como centro de estudios que tiene un papel protagónico en el crecimiento y desarrollo de las regiones.

La educación en el Huila en el siglo XIX, desde su estructuración como provincia, luego anexa al Estado de Cundinamarca, o parte del Estado Soberano del Tolima, siguió las normas del orden nacional en todo lo relacionado con el sistema educativo. Sin embargo, en la mayoría de los casos, no se pudieron aplicar tal como se presentaba, debido, entre otras razones, a la pobreza de los pobladores, a sistemas de comunicación muy incipientes, a un sector económico débil, a una región golpeada fuertemente por fenómenos naturales, como el sismo de 1827. Esto y otros factores determinaron la expedición de normas locales que en algunos aspectos se separaron de lo estipulado en las normas generales del Estado.

La Universidad Surcolombiana, como universidad departamental, surge tardíamente, respecto al desarrollo educativo del país. Mientras los primeros inicios de universidad se dieron en la época colonial, desde aproximadamente el año 1605, en el Huila el proyecto empieza a concretarse con la creación de ITUSCO en el año de 1970, producto de su lento desarrollo económico, político, social, cultural, científico y educativo que la mantuvo alejada del contexto nacional. Es probable que la discriminación que sintiera la provincia de Neiva desde su anexión al estado de Cundinamarca (que luego cuando pasa a formar parte del Estado Soberano del Tolima), incidiera en el atraso y abandono de la región por parte del gobierno central. También se considera que haya sido determinante su ubicación como región periférica y dependiente económicamente.

\section{Bibliografía}

Atcon, Rudolph (2005). "La Universidad Latinoamericana. Clave para un enfoque conjunto del desarrollo coordinado social, económico y educativo en América Latina". (Serie de documentos de trabajo No. 4) Bogotá, Universidad Nacional de Colombia, 2005.

Chaves García, José Ramón. La Universidad Pública española. Configuración actual y régimen jurídico de su profesorado. Madrid, Universidad de Oviedo, 1991. 
Cobban, Alan B (1975). The medieval universities: Their development and organization. Great Britain Harper and Row Publishers.

CoboSuero, Juan Manuel. La enseñanza superior en el mundo. Estudio comparado e hipótesis. Madrid: Narcea, 1979.

Colección Bicentenario. Historia hoy. Aprendiendo con el bicentenario. Bogotá, Ministerio de Educación Nacional, 2009.

Colmenares, Germán (1989). "La economía y la sociedad coloniales 1550-1800". En: Nueva historia de Colombia. Bogotá, T.8.

Cubillos Bernal, Julio Santiago (2007). Agustín Nieto Caballero y el proceso de apropiación del pensamiento pedagógico y filosófico de Jhon Dewey. Bogota: Programa editorial Universidad del Valle, Gimnasio Moderno de Bogotá, 2007.

Echeverry, Jesús Alberto. "El ocaso de la autonomía del maestro (1880-1903)". En: Educación y Cultura No. 9, Bogotá, 1986.

Forero, José. "Fechas históricas de Colombia". En: La sociedad y el universitario: un análisis del conflicto estudiantil y de la educación superior en Colombia. Editor: Manuel F. Neira. Bucaramanga, Universidad Industrial, 1971.

Gómez Oyarzún, Galo (1998). La universidad a través del tiempo. México, Universidad Iberoamericana.

Guerrero Gerardo (1998). "Universidad pública: Modernización y modernidad 1826-1880". En: Revista Historia de la Educación Colombiana. No.1.

HELG, Aline. (2006). La educación en Colombia: 1918-1957. Bogotá, Plaza y Janés.

HELG, Aline (1987). La educación en Colombia: 1918-1957. Bogotá, Plaza y Janés.

HELG, Aline. La Educación en Colombia 1958-1980. En: Nueva Historia de la Educación en Colombia. Vol. IV. 2001

HELG, Aline. "La educación en Colombia 1958-1980". En: Nueva historia de Colombia Vol. IV. Bogotá, Planeta, 1989.

Helgera, J. León. "La educación durante el primer gobierno de Mosquera". En: Revista Colombiana de Educación No.26, Bogotá,1993.

Indart, Juan Carlos (2005). El padre y el profesor. Bogotá, Cid.

lyangaPendi, Augusto. Historia de la universidad en Europa. Valencia, Universitat de Valencia, Cuadernos del Departamento de Educación Comparada e Historia de la Educación No. 42, 2000.

Jaramillo Uribe, Jaime . "La educación durante los gobiernos liberales. 1930-1946". En: Nueva historia de Colombia Vol. 4. Santa Fe de Bogotá, Planeta, 1998.

Jaramillo Uribe, Jaime . "El proceso de la educación en el Virreinato". En: Nueva historia de Colombia Vol. 1. Santa Fe de Bogotá, Planeta, 1998.

López Domínguez, Luis Horacio (comp.), Obra educativa de Santander (Bogotá: Fundación Francisco de Paula Santander, 1990. Decreto del 3 de octubre de 1826, Tomo III).

Le Bot, Ivon . "Elementos para la historia de la educación en Colombia en el siglo XX". En: Boletín mensual de estadística, No. 249, DANE, Bogotá, 1975.

Manual de Historia de Colombia. Tomo III. Bogotá: Círculo de lectores, 1982. Director científico Jaime Jaramillo Uribe.

Ramírez Bahamón, Jairo. Historia social de una utopía escolar: la educación en el Estado Soberano del Tolima 1861-1886. Neiva: Universidad Surcolombiana, 1998.

Ramírez Bahamón, Jairo. "La educación en el Huila a finales del siglo XIX: Monseñor Esteban Rojas Tobar, por la Regeneración y por la escuela 1885-1900". En: Historia General del Huila Vol. 4, 1996.

Ramírez Bahamón, Jairo. La escuela en la antigua provincia de Neiva 1819-1860. Neiva: Universidad Surcolombiana, 2000. 